NBER WORKING PAPER SERIES

\title{
SPACEY PARENTS: SPATIAL AUTOREGRESSIVE PATTERNS IN INBOUND FDI
}

\author{
Bruce A. Blonigen \\ Ronald B. Davies \\ Helen T. Naughton \\ Glen R. Waddell \\ Working Paper 11466 \\ http://www.nber.org/papers/w11466
}

\author{
NATIONAL BUREAU OF ECONOMIC RESEARCH \\ 1050 Massachusetts Avenue \\ Cambridge, MA 02138 \\ June 2005
}

Blonigen is also a Research Associate with the National Bureau of Economic Research. Corresponding author Davies: Department of Economics, University of Oregon, Eugene, OR 94703-1285; Phone: (541) 3464671; Fax: (541) 346-1243; Email: rdavies@uoregon.edu. We thank participants at the CES-Ifö's Venice Summer Institute's Workshop on "Recent Developments in International Trade: Globalization and the Multinational Enterprise". Any errors or omissions are the responsibilities of the authors. The views expressed herein are those of the author(s) and do not necessarily reflect the views of the National Bureau of Economic Research.

(O2005 by Bruce A. Blonigen, Ronald B. Davies, Helen T. Naughton, and Glen R. Waddell. All rights reserved. Short sections of text, not to exceed two paragraphs, may be quoted without explicit permission provided that full credit, including $\odot$ notice, is given to the source. 
Spacey Parents: Spatial Autoregressive Patterns in Inbound FDI

Bruce A. Blonigen, Ronald B. Davies, Helen T. Naughton, and Glen R. Waddell

NBER Working Paper No. 11466

June 2005

JEL No. F21, F23

\section{ABSTRACT}

Increasing attention has been given to the impact of third countries on outbound FDI to a given host country. Here, we consider potential third-country effects on inbound FDI. A simple model suggests two sources of such effects on a country's inbound FDI. First, it will tend to receive more FDI from parent countries proximate to large third countries. Second, FDI from third countries may increase or decrease FDI from the parent country in question depending on whether production spillovers or crowding out effects dominate. Using data on US inbound FDI from OECD countries during 19802000, we find strong evidence for parent market proximity effects. We find robust results for third country FDI effects only in a European subsample. There, crowding out effects dominate.

Bruce A. Blonigen

Department of Economics 1285 University of Oregon

Eugene, OR 94703-1285

and NBER

bruceb@uoregon.edu

Ronald B. Davies Department of Economics 1285 University of Oregon Eugene, OR 94703-1285 rdavies@uoregon.edu
Helen T. Naughton

Department of Economics 1285 University of Oregon Eugene, OR 94703-1285 htammela@uoregon.edu

Glen R. Waddell Department of Economics 1285 University of Oregon Eugene, OR 94703-1285 waddell@uoregon.edu 


\section{Introduction}

Of the many directions in the current work on foreign direct investment (FDI), the effort to expand our understanding of multinational enterprises (MNEs) to include the influence of third countries is one of the most promising. Working from a strong base of theory and evidence describing the influence of parent- and host-country factors on FDI, much of which is summarized in Caves (1996) and Markusen (2002), recent work examines the influence of additional potential host countries on the outbound FDI decision. Papers in this vein include those of Ekholm, Forslid, and Markusen (2003), Yeaple (2003), and Bergstrand and Egger (2004) who analyze what has been termed "export platform FDI." In contrast to Markusen's (1984) horizontal model in which the MNE serves each of its markets through a local plant, in the export platform model, the MNE establishes a single overseas plant in one of the many potential hosts. Output from this centrally-located plant is then sold in both the host and other nearby markets. Recent evidence by Blonigen, et. al. (2004) and Baltagi, Egger, and Pfaffermayr (2004) finds compelling evidence for this export platform motivation in outbound FDI data.

Although this work has focused on outward investment and the choice among host locations, it is just as important to recognize that third country effects may be important for inbound FDI as well. In this paper, we identify two potential channels for such effects using a simple model of the MNE. First, we show that the parent country's proximity to additional markets alters the margin of whether to service the host market through exports from parent or through FDI. When the parent country has low-cost access to large markets, this increases the opportunity cost of exporting to the host. Therefore, subsidiary production in the host will rise even though the host itself is not an 
export platform. We call this the parent market proximity effect, which contrasts with host country market proximity effects (often called market potential effects) in previous literature such as Head and Mayer (2004) and Blonigen, et. al. (2004). Second, when there are MNEs from many countries active in the host, they may influence each other. If the various MNEs compete for scarce resources, then FDI from any single parent country may be crowded out by FDI from other parent countries. Alternatively, if FDI from other parent countries provide positive production externalities in the host country through technological transfer or market linkages, then greater third country FDI could encourage FDI from the parent country in question.

This then suggests two testable hypotheses. First, we expect that more FDI will come from countries near large third-country markets. Second, more FDI from third countries in the host can mean more or less FDI from parent depending on whether spillover or crowding-out effects dominate. To analyze these issues, we turn to a dataset on US inbound FDI from twenty OECD countries over 1980-2000. We find strong evidence for parent market proximity effects - evidence that is robust to a variety of specifications. The effect of FDI from third countries, however, depends on the sample. When using our full OECD dataset, we find no robust result for this variable. When restricting the analysis to a European subsample - a subsample that excludes the geographically distant countries of Australia, Canada, and Japan - we find a robustly negative impact of third country FDI. Thus, at least for the European sample, it seems as if FDI from one country may crowd out investment from another.

This paper proceeds as follows. In Section 2, we sketch out a simple, partial equilibrium model of the multinational firm in order to frame our predictions. In Section 
3, we discuss our empirical strategy and data. Section 4 presents our results and Section 5 concludes.

\section{A Simple Model of the Multinational Firm}

In this section our goal is to frame our empirical methodology with a simple, partial equilibrium model of a multinational firm. While this model clearly lacks many of the general equilibrium properties that typify fully-specified models such as Markusen (2002) or Helpman, Melitz, and Yeaple (2004), our goal here is simply to elucidate some of the ways in which third-country effects may be important for a country's inbound FDI from a particular parent.

Consider a firm that produces in two countries, parent and host. ${ }^{1}$ Countries are numbered such that the host country is country 1 and the parent is country 2 . In addition, there is a third country 3 . The output from parent country 2 is produced at a total variable production $\operatorname{cost} C(Q)$ where $Q$ is the total amount produced in the parent country. ${ }^{2}$ This output can be sold in any of the three countries, where $Q_{i}$ is the amount of parentproduced output sold in country $i$. To do so, the firm must incur a per-unit shipping cost $t_{i} \geq 0$, where $t_{2}=0$, i.e. parent production can be sold in the parent country without additional cost. In addition to parent production, the multinational produces in the host, incurring the total variable production $\operatorname{cost} C^{*}\left(Q^{*} ; \Omega\right)$ where $Q^{*}$ is the total host production and $\Omega$ is a function of the other (non-modeled) MNEs active in the host

\footnotetext{
${ }^{1}$ In the interest of brevity, we assume that the firm is a multinational. Such decisions lie at the heart of many models of FDI as discussed by Markusen (2002). Our model could easily be broadened to include the choice of whether to go multinational or not. There, because of the need to cover additional fixed costs $\gamma_{1}$ when setting up the host plant, this choice would depend on host market size and the relative cost savings (avoiding $\mathrm{t}_{1}$ and the increasing parent marginal cost). Since formal presentation of this possibility does not significantly contribute to our goals for this section, we omit it.

${ }^{2}$ In the rest of this section we refer to parent country 2 as simply the "parent country."
} 
(more on this below). Both production cost functions are increasing, convex functions. ${ }^{3}$

We assume that all output from the host plant is sold in the host, i.e. that this is a purely horizontal MNE, in order to eliminate any effects that would arise from an exportplatform motivation for host production. We also assume that in equilibrium all quantities will be positive, implying that the firm does not import from the host. ${ }^{4}$

Defining $q_{i}$ as the total amount sold in each country, each country's local price is $P_{i}\left(q_{i} ; \beta_{i}\right)$. Note that for the host country $q_{1}=Q_{1}+Q^{*}$ whereas the total amount sold in the other two countries is equal to their respective $Q_{i}$. We assume that these inverse demand functions are decreasing in their respective quantities and that the associated marginal revenue functions are declining in quantity. ${ }^{5}$ The $\beta_{i}$ term in the inverse demand is a shift parameter. We assume that, all else equal, an increase in a country's $\beta$ increases both the price and the slope of the price function, i.e. where superscripts denote derivatives, that both $P_{i}^{\beta}$ and $P_{i}^{q_{i} \beta}$ are positive. These $\beta$ terms are intended to represent terms that increase the size of a given market; the bigger the market, for a given quantity, the higher and the less sensitive the price will be. Finally, in addition to its variable costs, each plant costs the firm a fixed cost $\gamma_{i}$ and the firm incurs a firm-level fixed cost $\alpha$.

The MNE's profits are given by:

$$
\Pi^{M N E}=\sum_{i=1}^{3} P_{i}\left(q_{i} ; \beta_{i}\right) q_{i}-C(Q)-C^{*}\left(Q^{*} ; \Omega\right)-\sum_{i=1}^{3} t_{i} Q_{i}-\gamma_{1}-\gamma_{2}-\alpha
$$

Profit maximization implies that:

\footnotetext{
${ }^{3}$ Note that this assumption differs from many models in which production is constant returns to scale (CRS). If we assume CRS production in our partial equilibrium model, then host production will not depend on third country variables, although it would still depend on $\Omega$.

${ }^{4}$ Our theory can certainly encompass this possibility, however. The primary change is that in increase trade costs between 1 and 2 would decrease the need for overseas production.

${ }^{5}$ This latter assumption is guaranteed if the inverse demand functions are concave.
} 


$$
P_{i}^{q_{i}}\left(q_{i} ; \beta_{i}\right) q_{i}+P_{i}\left(q_{i} ; \beta_{i}\right)=C^{Q}\left(\sum_{i=1}^{3} Q_{i}\right)+t_{i} \text { for } i=1,2,3
$$

and

$$
C^{* Q^{*}}\left(Q^{*} ; \Omega\right)=C^{Q}\left(\sum_{i=1}^{3} Q_{i}\right)+t_{1} .
$$

Equation (2) is the standard markup condition for a monopolist. Note that unlike many models of FDI, we ignoring competition in output markets with other firms (either domestic, foreign, or multinational). We take this partial equilibrium approach for simplicity since demonstrating these interactions is not the primary goal of our theory, which is instead to highlight the role of third countries. Equation (3) highlights the tradeoff of this horizontal firm between parent production (and exports) and host production.

From the four first order conditions, we can calculate how host production moves in response to changes in our exogenous parameters. This is given in the following proposition.

Proposition 1: Host production is:

a) increasing in country 1's transport cost,

b) decreasing in country 3's transport cost,

c) increasing in any country's market size.

Proof: It will prove convenient to define some notation. Denote the change in a country's marginal revenue with respect to the quantity sold there by:

$$
\tilde{P}_{i} \equiv P_{i}^{q_{i} q_{i}}\left(q_{i} ; \beta_{i}\right) q_{i}+2 P_{i}^{q_{i}}\left(q_{i} ; \beta_{i}\right)<0
$$

Also, define 


$$
\begin{array}{r}
\Phi \equiv C^{Q Q}(Q) C^{*} Q^{*} Q^{*}\left(Q^{*} ; \Omega\right)\left[\tilde{P}_{1} \tilde{P}_{2}+\tilde{P}_{1} \tilde{P}_{3}+\tilde{P}_{2} \tilde{P}_{3}\right] \\
-\tilde{P}_{1} \tilde{P}_{2} \tilde{P}_{3}\left[C^{Q Q}(Q)+C^{*} Q^{*} Q^{*}\left(Q^{*} ; \Omega\right)\right]>0
\end{array}
$$

Using equations (2) and (3), we can calculate the following comparative statics (dropping the arguments of functions):

$$
\begin{gathered}
\frac{d Q^{*}}{d t_{1}}=\Phi^{-1} \tilde{P}_{1}\left[C^{Q Q}\left(\tilde{P}_{2}+\tilde{P}_{3}\right)-\tilde{P}_{2} \tilde{P}_{3}\right]>0, \\
\frac{d Q^{*}}{d t_{3}}=\Phi^{-1}\left[-C^{Q Q} \tilde{P}_{1} \tilde{P}_{2}\right]<0, \\
\frac{d Q^{*}}{d \beta_{1}}=\Phi^{-1} \tilde{P}_{2} \tilde{P}_{3} C^{Q Q}\left[P_{1}^{q_{i} \beta} q_{1}+P_{1}^{\beta}\right]>0, \\
\frac{d Q^{*}}{d \beta_{2}}=\Phi^{-1} \tilde{P}_{1} \tilde{P}_{3} C^{Q Q}\left[P_{2}^{q_{i} \beta} q_{2}+P_{2}^{\beta}\right]>0,
\end{gathered}
$$

and

$$
\frac{d Q^{*}}{d \beta_{3}}=\Phi^{-1} \tilde{P}_{1} \tilde{P}_{2} C^{Q Q}\left[P_{3}^{q_{i} \beta} q_{3}+P_{3}^{\beta}\right]>0
$$

\section{Q.E.D.}

The intuition behind these results is straightforward. When the transport cost to the host rises, this lowers the relative marginal cost of host production compared to producing at parent and exporting. Thus the MNE shifts production to the host. When the transport cost to country 3 rises, it reduces exports from parent to country 3 . This frees up parentproduced output for exporting to the host, leading to a reduction in host output. When the host market size rises, this increases the return to selling there, thereby increasing host production (as well as exports from parent to the host). When the market size of either of 
the other countries rises, the MNE will divert parent output away from the host and replace a portion of this decline with increased host production.

This illustrates one way in which third countries can impact FDI in the host. When the parent country has easy access to large third markets, the firm's parent activities will be geared more heavily towards those markets. As a result, firms from such countries will expand host production to serve that particular market. The second way in which third countries can impact the MNE's decision is through the effect of their multinationals on the firm's host production costs, i.e. through $\Omega$. Again using the first order conditions, we find that:

$$
\frac{d Q^{*}}{d \Omega}=\Phi^{-1} C^{*} Q^{*} \Omega\left[\tilde{P}_{1} \tilde{P}_{2} \tilde{P}_{3}-C^{Q Q}\left[\tilde{P}_{1} \tilde{P}_{2}+\tilde{P}_{1} \tilde{P}_{3}+\tilde{P}_{2} \tilde{P}_{3}\right]\right]
$$

which has the opposite sign of $C^{*} Q^{*} \Omega$. If $C^{* Q^{*} \Omega}$ is positive, i.e. greater MNE activity by other firms increases this firm's marginal cost of host production, then more FDI from other countries will reduce the output of MNEs from the parent country. This would be consistent with a situation in which MNEs compete for scarce host resources.

Alternatively, if we were to embed this $\Omega$ in the host price function, such an impact could arise due to greater competition in the host. On the other hand, more FDI from other countries could lower the marginal cost of host production due to spillovers. As discussed by Blomström and Kokko (1998), there is a sizable body of evidence suggesting that multinationals provide positive production externalities to other firms, benefits which may well extend to other MNEs in the host. Given these conflicting possibilities, we have no a priori expectations on the net effect of third countries' FDI and therefore turn to the data for additional insights. 


\section{Empirical Methodology and Data}

In this section, we discuss our empirical specification and data.

\subsection{Empirical Specification}

Our empirical approach will utilize US inbound FDI data and apply a modification of the commonly-used gravity model of FDI. Ignoring time subscripts for notational purposes and where all non-discrete variables are measured in natural logs, our primary regression specification is given by:

$$
\begin{aligned}
F D I= & \alpha_{0}+\alpha_{1} \text { Parent Variables }+\alpha_{2} \text { Trends } \\
& +\alpha_{3} \text { Parent Market Proximity }+\rho \cdot W \cdot F D I+\varepsilon .
\end{aligned}
$$

As in other gravity specifications for FDI, including those of Eaton and Tamura (1994) and Brainard (1997), we include several controls for the parent country. Thus, Parent Variables in equation (12) includes parent GDP, parent population, and measures of trade frictions between parent and host. In addition, following the insights of Carr, Markusen, and Maskus (2001), we include a measure of parent country skill. Typically, gravity models include a comparable set of host country variables. In our case, since the US is always the host country, these variables were insignificant once trends were included. ${ }^{6}$ Therefore we omit these in favor of Trends, which is a quadratic time trend.

In addition to the standard set of controls guided by prior literature, the above theory also suggests the inclusion of two additional variables. The first of these is a measure of the parent country's proximity to non-host markets. In their study of Japanese outbound FDI into Europe, Head and Mayer (2004) use several different measures of host country market proximity and find that a distance-weighted sum of proximate countries'

\footnotetext{
${ }^{6}$ These alternative results are available upon request. The omitted variables include US GDP, population, openness, skill, and an index of investment barriers.
} 
GDPs provides the best fit for the data. ${ }^{7}$ Taking their lead, we construct a comparable variable, parent market proximity, which for parent country $i$ is equal to $\sum_{j \neq i} \frac{173}{d_{i j}} G D P_{j}$ where $d_{i j}$ is the distance between the parent country in question $(i)$ and other non-US countries $(j) .{ }^{8}$ Note that although the construction of this variable is analogous to the host market potential measure of Head and Thierry (2004) and Blonigen, et. al. (2004), its interpretation is quite different because of the parent versus host country distinction. In the previous papers, the authors analyze outbound FDI data and the variable measures the proximity of the host country to additional surrounding markets which can be served by exports from this host. In this paper, we are constructing a variable that measures proximity of the parent country to other surrounding markets and, thus, is a measure of the ease with which firms can export from their parent location. Also note that this variable differs from the distance between the parent country $i$ and the US, a standard gravity model control variable that we include separately. This parent market proximity variable captures two aspects of the theory. First, third country GDP $\left(G D P_{j}\right)$ corresponds to the demand shift parameter, $\beta_{3}$, in our theory section. Second, $t_{3}$, the trade costs between parent and country 3 , are captured by the distance between parent and this third country. A rise in $\beta_{3}$ or a fall in $t_{3}$ both would imply an increase in parent market proximity. Since the theory predicts that either change would increase FDI in the host, we expect that $\alpha_{3}>0$.

\footnotetext{
${ }^{7}$ Since our host country is the US in all observations, as with the other US variables, we exclude host market potential in favor of quadratic trends.

${ }^{8}$ In line with the FDI weighting matrix discussed below, the 173 is the shortest distance between country pairs, implying that Belgium's GDP gets a weight of one for the Netherlands and vice versa. Since this is a constant, this simply scales the estimated coefficient on parent market proximity.
} 
In addition to parent market proximity, we include information about concurrent FDI from other parent countries. This is done to investigate whether there is indeed any evidence supporting the $\Omega$ effect in the theory. The primary difficulty in doing so is that, due to the fact that FDI from $i$ affects FDI from $j$ and vice versa, there is an endogeneity problem that must be addressed. One possible approach is to construct instruments for the other countries' investment. An alternative, and the one we choose here, is the use of autoregressive spatial estimation. As detailed in Anselin (1988), this maximumlikelihood procedure deals with the endogeneity problem present in OLS. In equation (12), the effect of $\Omega$ is represented by $\rho \cdot W \cdot F D I$, where FDI is a vector of investment into the US and $\mathrm{W}$ is the spatial lag weighting matrix, which is an $n \times n$, block-diagonal matrix with each block capturing a single year's observations (where $n$ is the number of observations). In our baseline case, we weight FDI using a simple inverse distance function where the shortest distance within the sample (the 173 kilometers separating Brussels and Amsterdam) gets a weight of one and all other distances get a weight that declines with distance. This inverse distance weighting scheme results in a control variable for FDI from country $i$ in year $t$ of $\sum_{j \neq i} \frac{173}{d_{i j}} F D I_{j, t}$, i.e. a distance-weighted average of FDI from the other parent countries in year $t$. The coefficient on this term, $\rho$, is referred to as the spatial lag. If the spatial lag is negative, this would be consistent with the crowding out story discussed above in which more FDI from other locations implies less FDI from the parent country in question. A positive spatial lag would be consistent with the spillover story. Note that in either case, the spatial lag only captures the net effect of FDI from other countries and does not rule out coexistence of these mechanisms. Also note that this spatial lag indicates the impact of other countries' 
inbound FDI and does not consider the interaction of firms from country $i$ nor does it capture spillovers or crowding out by US firms (the effect of which is captured by the trend terms). As the particular choice of weighting scheme is ad hoc, we utilize several alternative functional forms below. Furthermore, it is not clear that we should weight FDI by distance if what matters for $\Omega$ is total FDI from other sources irrespective of where it comes from. Therefore, one of our alternative weighting schemes will consider this possibility.

Although spatial studies of outbound FDI have been undertaken by Coughlin and Segev (2000), Baltagi, Egger, and Pfaffermayr (2004) and Blonigen, et. al. (2004), to our knowledge this technique has yet to be applied to inbound FDI data. Therefore, we are the first to consider the interaction between FDI from various parent countries. In particular our use of inbound data implies an important difference in the interpretation of their spatial lag variable and ours. In their estimates, the spatial lag estimates the impact of FDI from a single parent country $i$ into third country $k$ on its FDI into $j$. In our estimates, the spatial lag captures the impact of FDI from third country $k$ into $j$ on FDI from parent country $i$ into $j$. Note that this also differs from the interpretation of the results of Head, Ries, and Swenson (1995), who find evidence of agglomeration of Japanese subsidiaries in the US, since there too the estimated effect is how FDI from a single source in one location depends on FDI from the same source in other locations.

\subsection{Data}

For our dataset, we use a panel of annual data on US inbound FDI from the major developed countries between 1980 and 2000 as listed in Table 1. We choose these data for several reasons. First, the FDI from these countries is more likely homogeneous and 
may be more comparable across parent countries. As noted by Blonigen and Davies (2004), combining rich and poor countries in FDI data can often lead to implausibly-sized coefficient estimates. Furthermore, since the motivations behind investment from developed and developing countries may be quite different, combining FDI from the two groups may introduce undesirable noise into the data. In addition, as demonstrated by Markusen and Maskus (2001) and Blonigen, Davies, and Head (2003), estimates relying on pooled outbound and inbound data can give very different results for variables such as skill when compared to separate regressions on each sub-sample. Our second reason for choosing these data is that, by restricting ourselves to a relatively small sample of countries, this greatly eases the computation time that spatial autoregressive techniques require. This is a particular issue when the weighting matrix gives positive weight to all countries in the sample, an issue we must grapple with in many of our specifications. Third, by utilizing this set of countries, it allows a better comparison to the results of Blonigen, et. al. (2004) who consider US outbound FDI to this same set of countries. Despite the limitations utilizing this group of countries causes, it is worth noting that in 2000 , the countries in our full sample constituted 88 percent of total US inbound FDI. Finally, one added benefit of using US inbound data is that, compared to European countries, the US is far less likely to be an export platform since most output by MNEs in the US is sold in the US.

Our dependent variable is the real stock of inward US FDI as reported by the Bureau of Economic Analysis. We use the FDI stock evaluated at historical cost and convert it into real millions of dollars using the chain-type price index for gross domestic 
investment from the Economic Report of the President. ${ }^{9}$ Availability of these data limit our time period to 1980 and later. Parent country real GDP per capita and population data come from Penn World Tables (PWT). These data run up to 2000. ${ }^{10}$ Our trade-cost measure is the inverse of the openness measure reported by the PWT, which itself is equal to exports plus imports divided by GDP. A secondary trade cost measure is the distance between the US and the parent country. It should be noted, however, that this distance can also capture the difficulty in managing a distant subsidiary and may therefore capture the impact of such a barrier to FDI. Distance is measured using great circle distances between capital cities, denominated in kilometers. ${ }^{11}$ Parent country skill is measured by the average years of schooling for those over age 25 , reported every five years for $1960-2000 .{ }^{12}$ We used linear interpolation to construct values for other years. Summary statistics for our data are found in Table 2 .

One admitted shortcoming of this dataset is that it utilizes country-level data, a potential issue since the theory of Section 2 does not provide clear guidelines in the mapping between an individual firm's decisions and a country's aggregate amount of FDI. This shortcoming plagues many studies of FDI, particularly those that seek to identify effects generated in firm-level models. Although firm-level studies do exist (e.g. Head and Mayer (2004)), the use of country level data is still popular in the literature. To the extent that more-aggregate country-level data mask heterogeneous patterns at the firm- or industry-level, it will bias our analysis toward not finding any statistically significant

\footnotetext{
${ }^{9}$ The BEA's FDI data can be found at http://www.bea.doc.gov/bea/di/dilfdibal.htm. The price deflator can be found at http://www.gpoaccess.gov/usbudget/fy05/sheets/b7.xls.

${ }^{10}$ The PWT Version 6.1 data are available online at http://pwt.econ.upenn.edu/php_site/pwt_index.php.

${ }^{11}$ With the exception of Belgium, these data were provided by Raymond Robertson at his website. Belgian distances were acquired from http://www.indo.com.

${ }^{12}$ Acquired from Barro and Lee (2000), International Data on Educational Attainment.
} 
effects. For example, crowding out effects may outweigh positive production externalities in some industries, with the opposite true in other industries. Such patterns in the data would make an estimate of the spatial lag likely insignificant when using country-level data. As we next show, despite this aggregation bias, we find generally statistically significant results using country-level data.

\section{Results}

In our estimation, we begin with the full OECD sample. Following this, we restrict ourselves to a European subsample in order to test the sensitivity of our results. In Blonigen, et. al. (2004), which used US outbound FDI, the results on the spatial lag term depend somewhat on whether geographic outliers such as Japan and Australia are included. Therefore it is important to look for comparable sensitivity in US inbound FDI.

\subsection{OECD Results}

Table 3 presents our initial results from the OECD sample. Column (1) provides the standard OLS gravity estimates so that we can determine to what extent they are sensitive to the inclusion of third country effects. As is common in gravity models of FDI, we find that most US inbound FDI comes from large, skilled economies. We also find that more FDI tends to come from countries with small populations. Under the log specification, this would be consistent with more FDI from wealthy countries (i.e.

holding GDP equal, those with smaller populations). In column (1) we also find that more FDI comes from countries near to the US, although as will be seen this finding is very sensitive. 
In column (2), we add parent market proximity to the baseline gravity specification. We find that it is both positive and significant, consistent with our hypothesis that a larger market surrounding the parent country increases the opportunity cost of exporting to the host, thus increasing FDI and affiliate production in the host country. Our other coefficients change little in terms of either significance or magnitude. The one exception is that the distance from the US becomes insignificant. In column (3), we omit the parent market proximity, but include the spatial lag in the baseline gravity specification. We find that the spatial lag is insignificant and that its inclusion does not greatly change our estimates relative to column (1). Finally, column (4) includes both the spatial lag and parent market proximity. Again, the spatial lag is insignificant. Otherwise, our results are quite similar to those in column (2) which indicate a significant positive effect of parent market proximity.

\subsection{Robustness to Alternative Weighting Schemes}

One potential issue with the spatial lag estimates in Table 3 is that the weighting matrix construction is ad hoc. In the theory, the term $\Omega$ represents the influence that FDI from third countries exerts on FDI from another country. There is no a priori reason to expect that this influence is an inverse function of geographic distance. Furthermore, the inverse distance weights used in Table 3 assign positive weight to all countries, regardless of their distance from the parent country in question. Finally, it seems just as possible that distance between parent countries should not factor into $\Omega$ at all and that what matters is simply the total FDI from third countries. To examine whether these alternatives provide a different picture of the effect of third country FDI, in Table 4 we 
use several alternative specifications for the weighting matrix used to construct the spatial lag term. ${ }^{13}$

The first alternative (the results of which are in column (1)), uses a negative exponential weight, i.e. for an observation from country $i$, the weight on FDI into the US from country $j$ is:

$$
w_{y}\left(d_{i, j}\right)=e^{-d_{i, j} / 1000} \forall i \neq j
$$

As with the inverse distance, this too assigns positive weight to all other parent countries. Therefore, the next alternative assigns zero weight to other parent countries $j$ beyond a certain distance from parent country $i$. In column (2), we use the weights:

$$
w_{y}\left(d_{i, j}\right)=\left(1-\left(\frac{d_{i, j}}{11,155}\right)^{2}\right)^{2} \forall i \neq j \text { if } d_{i, j} \leq 11,155 ; 0 \text { otherwise } .
$$

In our sample, the smallest maximum separation of any country-pair (the distance between Lisbon and Tokyo) is 11,155 kilometers whereas the largest maximum separation is 18,074 kilometers (the distance between Lisbon and Sydney). As such, this scheme gives positive weight only to those pairings closer than 11,155 . Because this weighting scheme uses the minimum maximum distance as a cutoff, with apologies to game theorists everywhere, we refer to this as the "minmax" weight. The third weighting scheme, found in column (3), is similar to the minmax weight in form but assigns positive weights to all countries except the pair with the greatest distance. This scheme is is given by:

$$
w_{y}\left(d_{i, j}\right)=\left(1-\left(\frac{d_{i, j}}{18,074}\right)^{2}\right)^{2} \forall i \neq j \text { if } d_{i, j} \leq 18,074 ; 0 \text { otherwise } .
$$

\footnotetext{
${ }^{13}$ Throughout Table 4 we use the same inverse-distance weighting scheme for parent market proximity. We do this to isolate the impact the weighting matrix has on the spatial lag's estimated coefficient.
} 
Since this weighting scheme uses the maximum maximum distance between countries as the cutoff point, we refer to it as the "maxmax" weight. Finally, column (4) does not weight by distance at all. Here, the weight is:

$$
w_{y}\left(d_{i, j}\right)=1 \forall i \neq j ; 0 \text { otherwise }
$$

implying that the spatial lag is the total FDI from all other countries $\mathrm{j} .{ }^{14}$ We refer to this as equal weights.

As Table 4 shows, similar to Table 3's column (4) which is repeated in Table 4, the magnitude and significance of the standard gravity model variables change little across the various weighting matrix specifications. Parent market proximity also does not change greatly across the various specifications, although in the maxmax results of column (3) it falls outside the standard significance levels. Thus, it appears that this too is reasonably robust to the way in which third country FDI is included in the regression. The spatial lag term, however, is quite dependent on the choice of weighting matrix. Across the five different weighting matrices, the spatial lag is negative twice, insignificant twice, and positive once. Thus, no clear-cut conclusions can be drawn regarding the potential impact or importance of third-country FDI in the OECD data. Although the specification with the highest log-likelihood is the equal-weight specification where the spatial lag is negative and significant, the difference in loglikelihoods is small. Unfortunately, as discussed by Anselin (1988), there is no good

\footnotetext{
${ }^{14}$ Note that with this scheme, unlike the others, we do not row standardize. This is because doing so converts this term into average FDI from countries other than $i$. By construction, this average is going to be bigger for countries with small amounts of FDI and smaller for countries with large amounts of FDI. This then will tend to lead to a negative coefficient on the spatial lag simply as a result of the variable's construction.
} 
mechanism for choosing a preferred weighting matrix. ${ }^{15}$ We must therefore conclude that, although the parent market proximity effect is reasonably robust in the OECD data, that the same is not true for the spatial lag.

\subsection{European Results}

As illustrated in Figure 1, nearly one-half of US inbound FDI in our sample comes from three countries: Australia, Canada, and Japan. One factor that sets these three countries apart from the others is their geographic isolation since the others are relatively tightly packed into Europe. To examine the extent to which these geographic outliers influence our results, we next restrict our dataset to the European countries as illustrated in Figure 2. ${ }^{16}$ In Table 5, we repeat our regressions from Table 3 using this subsample. In column (1), we include only the standard set of gravity model variables. As in the full sample, we find that most FDI comes from large, skilled, open parent countries. Unlike the OECD results, parent population is insignificant. Also unlike the OECD results, we find that, as in most studies of FDI, distance from the US is a detriment to FDI and that this result is robust to alternative specifications. ${ }^{17}$

Turning to the parent market proximity variable, as in OECD regressions, it is positive and significant. A key difference between the European and OECD results, however, is that including parent market proximity does impact the coefficients of two gravity model variables - parent GDP and parent population. In both columns (2) and (4), including parent market proximity reduces the point estimate of parent GDP by about

\footnotetext{
${ }^{15}$ As Anselin (1988) discusses in Chapter 14, depending on the criterion used, the relative ranking of weighting matrices can change dramatically. Furthermore, since choosing a different weighting matrix is tantamount to choosing a different control variable, such comparisons do not have analogies to comparisons between restricted and unrestricted estimations.

${ }^{16}$ In 2000 , this subsample comprised two-thirds of total US inbound FDI therefore we are still discussing a large share of overall US inbound FDI.

${ }^{17}$ This change is primarily due to exclusion of Canada from the dataset.
} 
half. This suggests that, at least in this sample, excluding this variable tends to overstate the importance of the parent country's size. In addition, including parent market proximity switches the sign of parent population from negative to positive. In fact, in column (4), parent population becomes significantly positive. Although this latter change is fairly weak (as will be seen in Table 6), it again suggests that including measures of the parent market's proximity to additional markets may be important for estimating FDI activity.

Unlike the OECD results, the European data yields a significantly negative spatial lag. This is consistent with a crowding out story in which the presence of multinationals from other countries decreases the net benefit of FDI from the country in question. Comparing columns (3) and (4), this effect grows stronger in both magnitude and significance when the market potential variable is included. Thus, as in Blonigen, et. al. (2004), the exclusion of the geographic outliers tends to increase the magnitude of the estimated spatial lag. Given the estimated spatial lag coefficient in our preferred specification of column (4), a one percent rise in FDI by all other parent countries decreases FDI by the remaining parent country by 0.85 percent. This suggests that to the extent that crowding out occurs, it happens on a less than one-to-one basis.

In Table 6, we again use four alternative weighting matrices for the spatial lag. ${ }^{18}$ Note that both the minmax and the maxmax weights were adjusted to reflect changes in the maximum distances the sample change created. Here, our results change little across the various weighting matrices. In each, parent market proximity is significantly positive and the spatial lag is significantly negative. Thus, regardless of how we combine third

\footnotetext{
${ }^{18}$ As in Table 4, throughout Table 6 we use the same inverse-distance weighting scheme for parent market proximity.
} 
countries' FDI, we find that more FDI comes from countries nearer to other large markets. Furthermore, our estimates suggest that more FDI from one European country appears to crowd out FDI from another and that this effect is less than one-to-one. The only gravity variable that changes across specifications is the parent population which, as noted above, is only significant when using the inverse distance weights.

Finally, in unreported results, we in turn dropped Belgium, the Netherlands, the Scandinavian countries, and those countries which individually comprised less than one percent of US inbound FDI from Europe. ${ }^{19}$ In each of these, we found a positive parent market proximity coefficient and a negative spatial lag, both of which were significant at the one percent level. This indicates that the European results are robust to sub-samples within Europe and that the exclusion of the three geographic outliers is the driving force of the difference between the OECD and European samples.

\section{Conclusion}

The goal of this paper has been to provide some initial insights into how the presence of other parent countries might affect how much FDI a particular parent country undertakes. This line of thought is intended to complement the existing work on how the presence of additional host countries affects how much FDI a given host receives. Using a simple model, we suggest two avenues for such effects: parent market proximity and interaction between FDI from different parents. Using samples of OECD and European FDI into the US, we find strong evidence for a positive effect of parent market proximity. However, only in the European subsample do we find a robust effect of FDI from other

\footnotetext{
${ }^{19}$ The Scandinavian countries excluded were Denmark, Norway, Sweden, and Finland. The countries with less than one percent were Portugal, Turkey, Greece, Norway, Spain, Denmark, Finland, Austria and Italy.
} 
countries. There, we find that the more FDI that other countries have in the US, the less FDI a given parent will have. This would be consistent with increased competition in input or output markets by these other countries' multinationals.

This latter effect suggests that such crowding out appears to be the dominate force at play in the European sample. However, there are two critical caveats that must be noted. First, this is only the net effect from third country FDI. As such it should not be interpreted as implying that no positive production externalities exist. Second, we are dealing with highly aggregated data for the purpose of comparing our results to the bulk of the literature. This level of aggregation may mask important interactions at the industry or firm level that we do not capture. Nevertheless, our hope is that the present results highlight the potential usefulness of considering the impact of other parent countries on FDI and that they spur both more detailed theory and empirical work in this area. 
Table 1: Sample of Countries and Number of Years in the Sample

\begin{tabular}{llc}
\hline Country & Years in Sample & $\begin{array}{c}\text { Number of Years in } \\
\text { the Sample }\end{array}$ \\
\hline Australia & $1980-2000$ & 21 \\
Austria & $1980-2000$ & 21 \\
Belgium & $1980-2000$ & 21 \\
Canada & $1980-2000$ & 21 \\
Denmark & $1980-2000$ & 21 \\
Finland & $1980-2000$ & 21 \\
France & $1980-2000$ & 21 \\
Germany & $1980-2000$ & 21 \\
Greece & $1980-84,1986-2000^{*}$ & 20 \\
Ireland & $1980-84,1986-2000^{*}$ & 20 \\
Italy & $1980-2000$ & 21 \\
Japan & $1980-2000$ & 21 \\
Netherlands & $1980-2000$ & 21 \\
Norway & $1980-2000$ & 21 \\
Portugal & $1980-83,1986-89,1992,1994-95^{*}$ & 11 \\
Spain & $1980-2000$ & 21 \\
Sweden & $1980-2000$ & 21 \\
Switzerland & $1980-2000$ & 21 \\
Turkey & $1984-2000^{*}$ & 17 \\
United Kingdom & $1980-2000$ & 21 \\
\hline
\end{tabular}

* Missing years are due to one of two reasons: either FDI data were censored by the BEA due to confidentiality, or FDI stock reported was zero or negative.

Table 2: Descriptive Statistics (Full Sample)

\begin{tabular}{|c|c|c|c|c|}
\hline Variable & Mean & $\begin{array}{l}\text { Standard } \\
\text { Deviation }\end{array}$ & Minimum & Maximum \\
\hline FDI & 20,895 & 35,271 & 1 & 229,509 \\
\hline Parent GDP (\$millions) & 482 & 601 & 19 & 3,290 \\
\hline Parent Population (thousands) & 30,495 & 31,957 & 3,401 & 126,919 \\
\hline Parent Trade Costs & 0.022 & 0.012 & 0.005 & 0.070 \\
\hline Parent Skill & 8.479 & 1.841 & 3.264 & 11.860 \\
\hline Parent Distance from US $(\mathrm{km})$ & 7,018 & 2,771 & 734 & 15,958 \\
\hline $\begin{array}{l}\text { Parent Market Proximity } \\
\text { (\$millions) }\end{array}$ & 1,060 & 732 & 58 & 3,618 \\
\hline
\end{tabular}


Table 3: Spatial Analysis of US Inbound FDI.

\begin{tabular}{|l|l|l|l|l|}
\hline & \multicolumn{2}{|c|}{ OLS } & \multicolumn{2}{c|}{ Spatial ML } \\
\hline Independent variable & \multicolumn{1}{|c|}{$(1)$} & \multicolumn{1}{c|}{$(2)$} & \multicolumn{1}{c|}{$(3)$} & \multicolumn{1}{c|}{$(4)$} \\
\hline Ln(Parent GDP) & 2.840 & 2.652 & 2.790 & 2.623 \\
\hline & $(0.280)^{* * *}$ & $(0.288)^{* * *}$ & $(0.282)^{* * *}$ & $(0.288)^{* * *}$ \\
\hline Ln(Parent Population) & -1.039 & -0.911 & -1.016 & -0.899 \\
\hline & $(0.297)^{* * *}$ & $(0.299)^{* * *}$ & $(0.294)^{* * *}$ & $(0.296)^{* * *}$ \\
\hline Ln(Parent Trade Cost) & -2.006 & -1.582 & -1.903 & -1.523 \\
\hline & $(0.152)^{* * *}$ & $(0.225)^{* * *}$ & $(0.188)^{* * *}$ & $(0.242)^{* * *}$ \\
\hline Ln(Parent Skill) & 4.469 & 4.760 & 4.482 & 4.760 \\
\hline & $(0.349)^{* * *}$ & $(0.365)^{* * *}$ & $(0.345)^{* * *}$ & $(0.360)^{* * *}$ \\
\hline Ln(Distance from US in km) & 0.174 & 0.079 & 0.147 & 0.063 \\
\hline & $(0.095)^{*}$ & $(0.101)$ & $(0.099)$ & $(0.104)$ \\
\hline Trend & -0.159 & -0.164 & -0.161 & -0.166 \\
\hline & $(0.037)^{* * *}$ & $(0.036)^{* * *}$ & $(0.036)^{* * *}$ & $(0.036)^{* * *}$ \\
\hline Trend ${ }^{2}$ & 0.002 & 0.002 & 0.001 & 0.002 \\
\hline & $(0.001)$ & $(0.001)$ & $(0.001)$ & $(0.002)$ \\
\hline Spatially Weighted FDI & & & 0.105 & 0.073 \\
\hline (i.e., $\left.W^{*} F D I\right)$ & & & $(0.116)$ & $(0.118)$ \\
\hline Parent Market Proximity & & 0.230 & & 0.224 \\
\hline & & $(0.091)^{* *}$ & & $(0.090)^{* *}$ \\
\hline Constant & -54.127 & -54.602 & -53.572 & -54.205 \\
\hline & $(2.511)^{* * *}$ & $(2.501)^{* * *}$ & $(2.556)^{* * *}$ & $(2.553)^{* * *}$ \\
\hline Observations & 404 & 404 & 404 & 404 \\
\hline Adjusted ${ }^{2} /$ Log-Likelihood & .85 & .86 & -549.81 & -546.75 \\
\hline Stard
\end{tabular}

Standard errors in parentheses.

* significant at $10 \%$; $* *$ significant at $5 \%$; ** significant at $1 \%$ 
Table 4: Spatial Analysis of US Inbound FDI—Sensitivity Tests.

\begin{tabular}{|l|l|l|l|l|l|}
\hline & \multicolumn{1}{|c|}{ Table 3 } & \multicolumn{4}{|c|}{ Alternative Weighting Matrices } \\
\hline Independent variable & \multicolumn{1}{|c|}{$(4)$} & \multicolumn{1}{|c|}{$(1)$} & \multicolumn{1}{c|}{$(2)$} & \multicolumn{1}{c|}{$(3)$} & \multicolumn{1}{c|}{$(4)$} \\
\hline Ln(Parent GDP) & 2.623 & 2.496 & 2.651 & 2.647 & 2.477 \\
\hline & $(0.288)^{* * *}$ & $(0.294)^{* * *}$ & $(0.285)^{* * *}$ & $(0.281)^{* * *}$ & $(0.279)^{* * *}$ \\
\hline Ln(Parent Population) & -0.899 & -0.781 & -0.909 & -0.930 & -0.868 \\
\hline & $(0.296)^{* * *}$ & $(0.301)^{* * *}$ & $(0.296)^{* * *}$ & $(0.292)^{* * *}$ & $(0.287)^{* * *}$ \\
\hline Ln(Parent Trade Cost) & -1.523 & -1.387 & -1.576 & -1.669 & -1.449 \\
\hline & $(0.242)^{* * *}$ & $(0.242)^{* * *}$ & $(0.235)^{* * *}$ & $(0.223)^{* * *}$ & $(0.218)^{* * *}$ \\
\hline Ln(Parent Skill) & 4.760 & 4.806 & 4.761 & 4.669 & 4.398 \\
\hline & $(0.360)^{* * *}$ & $(0.359)^{* * *}$ & $(0.361)^{* * *}$ & $(0.358)^{* * *}$ & $(0.358)^{* * *}$ \\
\hline Ln(Distance from US) & 0.063 & -0.015 & 0.075 & 0.163 & 0.065 \\
\hline & $(0.104)$ & $(0.110)$ & $(0.114)$ & $(0.105)$ & $(0.097)$ \\
\hline Trend & -0.166 & -0.170 & -0.165 & -0.131 & 0.033 \\
\hline & $(0.036)^{* * *}$ & $(0.036)^{* * *}$ & $(0.037)^{* * *}$ & $(0.038)^{* * *}$ & $(0.053)$ \\
\hline Trend ${ }^{2}$ & 0.002 & 0.002 & 0.002 & 0.004 & 0.002 \\
\hline $\begin{array}{l}\text { Spatially Weighted } \\
\text { FDI }\end{array}$ & $(0.002)$ & $(0.001)$ & $(0.001)$ & $(0.002)^{* *}$ & $(0.001)$ \\
\hline \multicolumn{1}{|c|}{ (i.e., $\left.W^{*} F D I\right)$} & 0.073 & 0.143 & 0.007 & -0.444 & -0.068 \\
\hline Parent Market & $(0.118)$ & $(0.072)^{* *}$ & $(0.088)$ & $(0.181)^{* *}$ & $(0.014)^{* * *}$ \\
\hline \multicolumn{1}{|c|}{ Proximity } & 0.224 & 0.312 & 0.236 & 0.118 & 0.221 \\
\hline Constant & $(0.090)^{* *}$ & $(0.098)^{* * *}$ & $(0.112)^{* *}$ & $(0.100)$ & $(0.087)^{* *}$ \\
\hline & -54.205 & -54.116 & -54.681 & -49.915 & -42.092 \\
\hline Observations & $(2.553)^{* * *}$ & $(2.470)^{* * *}$ & $(2.667)^{* * *}$ & $(3.102)^{* * *}$ & $(3.486)^{* * *}$ \\
\hline $\begin{array}{l}\text { Adjusted } \mathrm{R}^{2} / \mathrm{Log}- \\
\text { Likelihood }\end{array}$ & 404 & 404 & 404 & 404 & 404 \\
\hline Stard & -546.75 & -544.97 & -546.93 & -543.71 & -535.05 \\
\hline
\end{tabular}

Standard errors in parentheses.

$*$ significant at $10 \% ;{ }^{* *}$ significant at $5 \% ; * * *$ significant at $1 \%$ 
Table 5: Spatial Analysis of US Inbound FDI from European OECD.

\begin{tabular}{|l|l|l|l|l|}
\hline & \multicolumn{2}{|c|}{ OLS } & \multicolumn{2}{c|}{ Spatial ML } \\
\hline Independent variable & \multicolumn{1}{|c|}{$(1)$} & \multicolumn{1}{c|}{$(2)$} & \multicolumn{1}{c|}{$(3)$} & \multicolumn{1}{c|}{$(4)$} \\
\hline Ln(Parent GDP) & 1.782 & 0.968 & 1.832 & 0.907 \\
\hline & $(0.297)^{* * *}$ & $(0.285)^{* * *}$ & $(0.293)^{* * *}$ & $(0.260)^{* * *}$ \\
\hline Ln(Parent Population) & -0.082 & 0.302 & -0.076 & 0.444 \\
\hline & $(0.307)$ & $(0.282)$ & $(0.302)$ & $(0.258)^{*}$ \\
\hline Ln(Parent Trade Cost) & -1.729 & -0.384 & -1.926 & -0.716 \\
\hline & $(0.192)^{* * *}$ & $(0.234)$ & $(0.220)^{* * *}$ & $(0.219)^{* * *}$ \\
\hline Ln(Parent Skill) & 4.915 & 4.626 & 4.925 & 4.575 \\
\hline & $(0.370)^{* * *}$ & $(0.337)^{* * *}$ & $(0.363)^{* * *}$ & $(0.307)^{* * *}$ \\
\hline Ln(Distance from US in km) & -4.350 & -3.317 & -4.606 & -3.972 \\
\hline & $(0.554)^{* * *}$ & $(0.516)^{* * *}$ & $(0.564)^{* * *}$ & $(0.482)^{* * *}$ \\
\hline Trend & -0.108 & -0.173 & -0.100 & -0.164 \\
\hline & $(0.038)^{* * *}$ & $(0.036)^{* * *}$ & $(0.038)^{* * *}$ & $(0.033)^{* * *}$ \\
\hline Trend ${ }^{2}$ & 0.002 & 0.005 & 0.003 & 0.008 \\
\hline & $(0.002)$ & $(0.001)^{* * *}$ & $(0.002)^{*}$ & $(0.001)^{* * *}$ \\
\hline Spatially Weighted FDI & & & -0.224 & -0.849 \\
\hline (i.e., $\left.W^{*} F D I\right)$ & & & $(0.130)^{*}$ & $(0.134)^{* * *}$ \\
\hline Parent Market Proximity & & 1.638 & & 2.142 \\
\hline & & $(0.191)^{* * *}$ & & $(0.191)^{* * *}$ \\
\hline Constant & -3.717 & -28.527 & -1.606 & -28.152 \\
\hline & $(6.509)$ & $(6.564)^{* * *}$ & $(6.507)$ & $(5.984)^{* * *}$ \\
\hline Observations & 341 & 341 & 341 & 341 \\
\hline Adjusted ${ }^{2} /$ Log-Likelihood & .86 & .89 & -449.09 & -397.25 \\
\hline Stard
\end{tabular}

Standard errors in parentheses.

* significant at $10 \%$; $* *$ significant at $5 \% ; * * *$ significant at $1 \%$ 
Table 6: Spatial Analysis of US Inbound FDI-Sensitivity Tests from European OECD.

\begin{tabular}{|l|l|l|l|l|l|}
\hline & \multicolumn{1}{|c|}{ Table 5 } & \multicolumn{4}{|c|}{ Alternative Weighting Matrices } \\
\hline Independent variable & \multicolumn{1}{|c|}{$(4)$} & \multicolumn{1}{|c|}{$(1)$} & \multicolumn{1}{|c|}{$(2)$} & \multicolumn{1}{c|}{$(3)$} & \multicolumn{1}{c|}{$(4)$} \\
\hline Ln(Parent GDP) & 0.907 & 1.212 & 1.753 & 1.184 & 0.874 \\
\hline & $(0.260)^{* * *}$ & $(0.270)^{* * *}$ & $(0.332)^{* * *}$ & $(0.277)^{* * *}$ & $(0.274)^{* * *}$ \\
\hline Ln(Parent Population) & 0.444 & 0.066 & -0.467 & 0.021 & 0.298 \\
\hline & $(0.258)^{*}$ & $(0.267)$ & $(0.328)$ & $(0.278)$ & $(0.270)$ \\
\hline Ln(Parent Trade Cost) & -0.716 & -0.534 & -0.498 & -0.393 & -0.316 \\
\hline & $(0.219)^{* * *}$ & $(0.220)^{* *}$ & $(0.225)^{* *}$ & $(0.223)^{*}$ & $(0.225)$ \\
\hline Ln(Parent Skill) & 4.575 & 4.412 & 4.260 & 4.335 & 4.318 \\
\hline & $(0.307)^{* * *}$ & $(0.317)^{* * *}$ & $(0.334)^{* * *}$ & $(0.329)^{* * *}$ & $(0.330)^{* * *}$ \\
\hline Ln(Distance from US) $)$ & -3.972 & -4.783 & -5.322 & -4.700 & -3.184 \\
\hline & $(0.482)^{* * *}$ & $(0.559)^{* * *}$ & $(0.692)^{* * *}$ & $(0.612)^{* * *}$ & $(0.495)^{* * *}$ \\
\hline Trend & -0.164 & -0.157 & -0.194 & -0.125 & -0.043 \\
\hline & $(0.033)^{* * *}$ & $(0.033)^{* * *}$ & $(0.034)^{* * *}$ & $(0.036)^{* * *}$ & $(0.045)$ \\
\hline Trend ${ }^{2}$ & 0.008 & 0.007 & 0.007 & 0.007 & 0.005 \\
\hline & $(0.001)^{* * *}$ & $(0.001)^{* * *}$ & $(0.001)^{* * *}$ & $(0.001)^{* * *}$ & $(0.001)^{* * *}$ \\
\hline $\begin{array}{l}\text { Spatially Weighted } \\
\text { FDI }\end{array}$ & -0.849 & -0.752 & -0.400 & -0.721 & -0.061 \\
\hline \multicolumn{1}{|c|}{ (i.e., $\left.W^{*} F D I\right)$} & $(0.134)^{* * *}$ & $(0.146)^{* * *}$ & $(0.097)^{* * *}$ & $(0.190)^{* * *}$ & $(0.013)^{* * *}$ \\
\hline Parent Market & 2.142 & 1.808 & 1.561 & 1.450 & 1.571 \\
\hline \multicolumn{1}{|c|}{ Proximity } & $(0.191)^{* * *}$ & $(0.181)^{* * *}$ & $(0.183)^{* * *}$ & $(0.188)^{* * *}$ & $(0.183)^{* * *}$ \\
\hline Constant & -28.152 & -16.078 & -13.371 & -8.335 & -19.842 \\
\hline & $(5.984)^{* * *}$ & $(6.578)^{* *}$ & $(7.267)^{*}$ & $(8.207)$ & $(6.575)^{* * *}$ \\
\hline Observations & 341 & 341 & 341 & 341 & 341 \\
\hline $\begin{array}{l}\text { Adjusted } \mathrm{R}^{2} / \text { Log- } \\
\text { Likelihood }\end{array}$ & -397.25 & -403.08 & -407.99 & -408.69 & -406.40 \\
\hline Stard & & & & & \\
\hline
\end{tabular}

Standard errors in parentheses.

* significant at $10 \%$; ** significant at $5 \%$; ** significant at $1 \%$ 


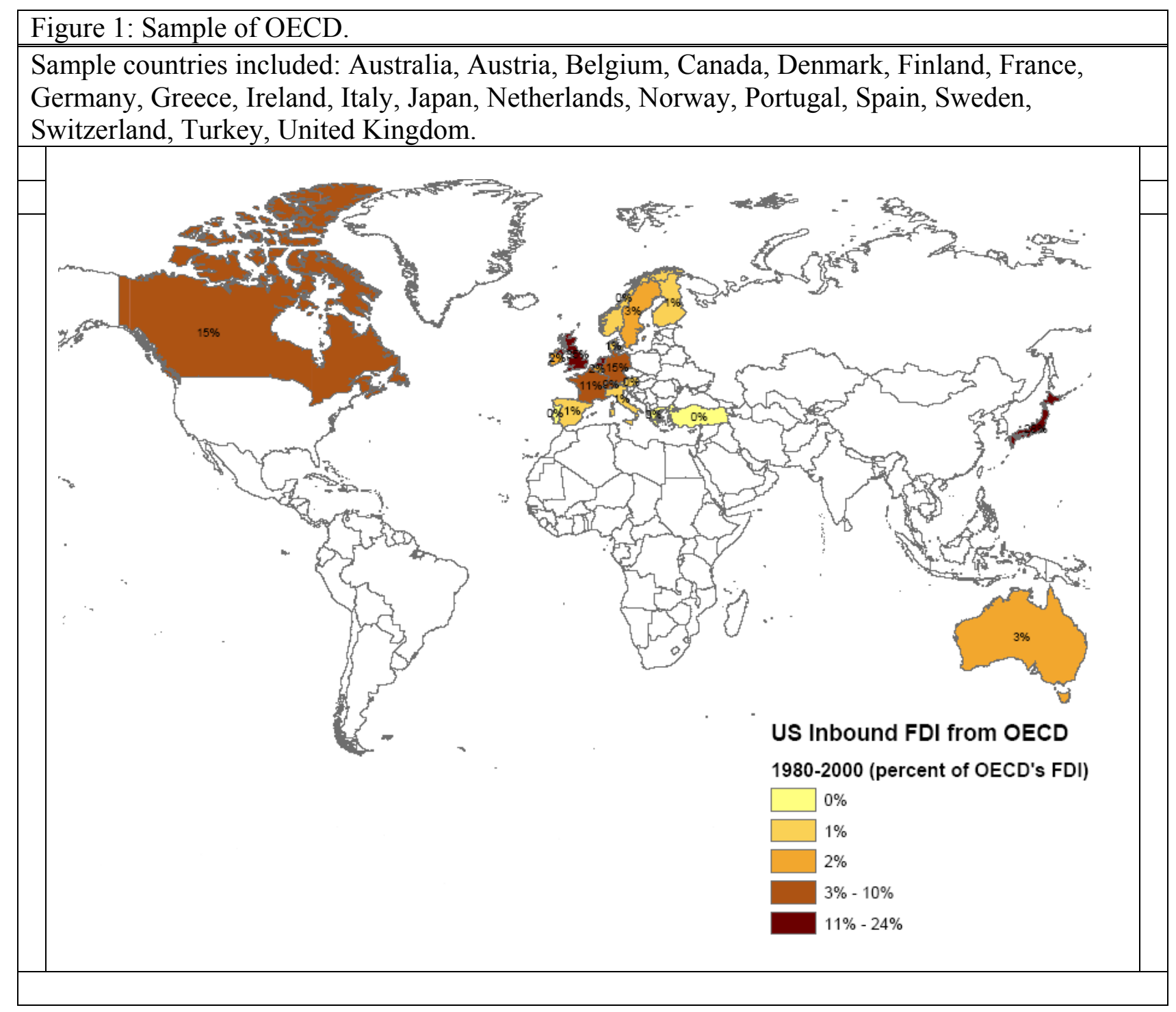




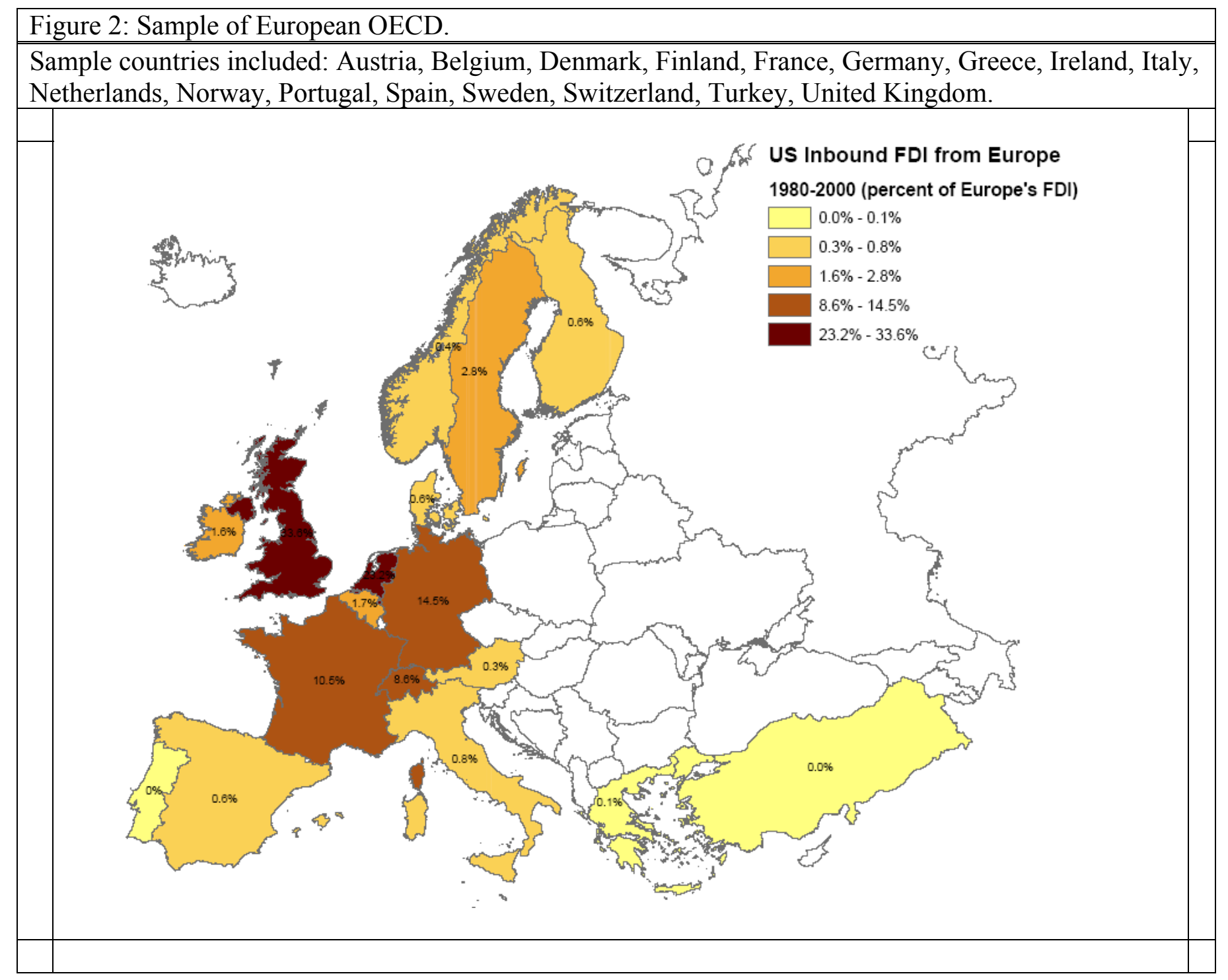




\section{References}

Anselin, Luc. (1988) Spatial Econometrics: Methods and Models, Kluwer Academic Publishers: Boston, MA.

Baltagi, Badi H., Peter Egger, and Michael Pfaffermayr. (2004) "Estimating Models of Complex FDI: Are There Third-Country Effects?" Mimeo.

Barro, Robert and J.W. Lee. (1996) "International Measures of Schooling Years and Schooling Quality." American Economic Review: Papers and Proceedings 86, 218-23.

Bergstrand, Jeffrey H. and Peter Egger. (2004) "A Theoretical and Empirical Model of International Trade and Foreign Direct Investment with Outsourcing: Part I, Developed Countries." Mimeo.

Blomström, Magnus and Ari Kokko. (1998) "Multinational Corporations and Spillovers," Journal of Economic Surveys 12, 247-77.

Blonigen, Bruce A. and Ronald B. Davies. (2004) "The Effects of Bilateral Tax Treaties on US FDI Activity," International Tax and Public Finance 11(5), 601-22.

Blonigen, Bruce A., Ronald B. Davies, Glen R. Waddell, and Helen T. Naughton. (2004). "FDI in Space: Spatial Autoregressive Relationships in Foreign Direct Investment," Working Paper

Brainard, S. Lael. (1997) "An Empirical Assessment of the Proximity-Concentration Trade-off Between Multinational Sales and Trade," American Economic Review 87(4): $520-44$

Carr, David L., James R. Markusen, and Keith E. Maskus. (2001) "Estimating the Knowledge-Capital Model of the Multinational Enterprise." American Economic Review 91(3), 693-708.

Caves, Richard E. (1996). Multinational enterprise and economic analysis. New York: Cambridge Press.

Coughlin, Cletus and Eran Segev. (2000) "Foreign Direct Investment in China: A Spatial Econometric Study." The World Economy 23 (1), 1-23

Eaton, Jonathan and Akiko Tamura. (1994) "Bilateralism and Regionalism in Japanese and US Trade and Direct Foreign Investment Patterns," Journal of the Japanese and International Economies 8(4), 478-510.

Ekholm, Karolina, Rikard Forslid, and James R. Markusen. (2003) "Export-Platform Foreign Direct Investment,” NBER Working Paper No. 9517. 
Head, Keith and Thierry Mayer. (2004) "Market Potential and the Location of Japanese Investment in the European Union," Review of Economics and Statistics.

Head, Keith, John Ries, and Deborah Swenson. (1995) “Agglomeration Benefits and Location Choice: Evidence from Japanese Manufacturing Investments in the United States," Journal of International Economics 38(3-4), 223-47.

Helpman, Elhanan, Marc J. Melitz, and Stephen R. Yeaple. (2004) "Export Versus FDI with Heterogeneous Firms," American Economic Review 94(1), 300-16.

Markusen, James R. (1984) "Multinationals, Multi-Plant Economies, and the Gains from Trade," Journal of International Economics 16(3-4), 205-26.

Markusen, James R. (2002) Multinational Firms and the Theory of International Trade. Cambridge and London: MIT Press.

Markusen, James R. and Keith E. Maskus. (2001) "Multinational Firms: Reconciling Theory and Evidence," in Magnus Blomström and Linda S. Goldberg, eds., Topics in Empirical International Economics: A Festschrift in Honor of Robert E. Lipsey. Chicago, IL: University of Chicago Press for National Bureau of Economic Research.

Yeaple, Stephen R. (2003) “The Complex Integration Strategies of Multinationals and Cross Country Dependencies in the Structure of Foreign Direct Investment," Journal of International Economics 60(2), 293-314. 